\title{
Heat transfer performance uniformity factor for the basement floor made of brick vaults in historic buildings
}

\author{
Vera Murgul $^{1,2, *}$ \\ ${ }^{1}$ Moscow State University of Civil Engineering, Yaroslavskoe shosse, 26, Moscow, 129337, Russia \\ ${ }^{2}$ Peter the Great St. Petersburg Polytechnic University, Politechnicheskaya st., 29, St. Petersburg, \\ 195251, Russia
}

\begin{abstract}
The paper exposes the calculation of Heat transfer performance uniformity factor for the basement floor made of brick vaults in residential historic buildings. It was determined that the temperature pattern on the floor surface of the premise could be characterized as uniform one. Heat transfer performance uniformity factor for the considered basement floor design can be ignored during the thermotechnical calculations. Thermal resistance calculation is performed for the overlap structure with the smallest thickness.
\end{abstract}

\section{Introduction}

Energy efficient reconstruction of historic buildings is usually accompanied by a heat insulation of the building envelope. If the basement is unheated, the problem of the basement floor insulation comes up (in the case of proven need). The paper exposes the determination thermotechnical uniformity coefficient for the basement floor over steel beams with brick vaults filling. The result of this study can be used for designing the insulation of basement floors in historic buildings [1-4].

\section{Materials and methods}

In residential buildings built in the late XIX - early XX centuries, the most common basement floor structure was the slab over steel beams (Figure 1) [5]. Filling between the beams can consist of the following structures (Figures 2, 3) [6, 7]:

- of the brick vaults with a thickness of $1 / 4$ - 1/2 bricks (Figure 2,a);

- concrete (Figure 2, b) or reinforced concrete vaults with a 7-8 cm thickness;

- of flat reinforced concrete fillings with haunches (Figure 2, c), and without (Fig.2, d).

\footnotetext{
${ }^{*}$ Corresponding author: vera.murgul@mail.ru
} 
a)

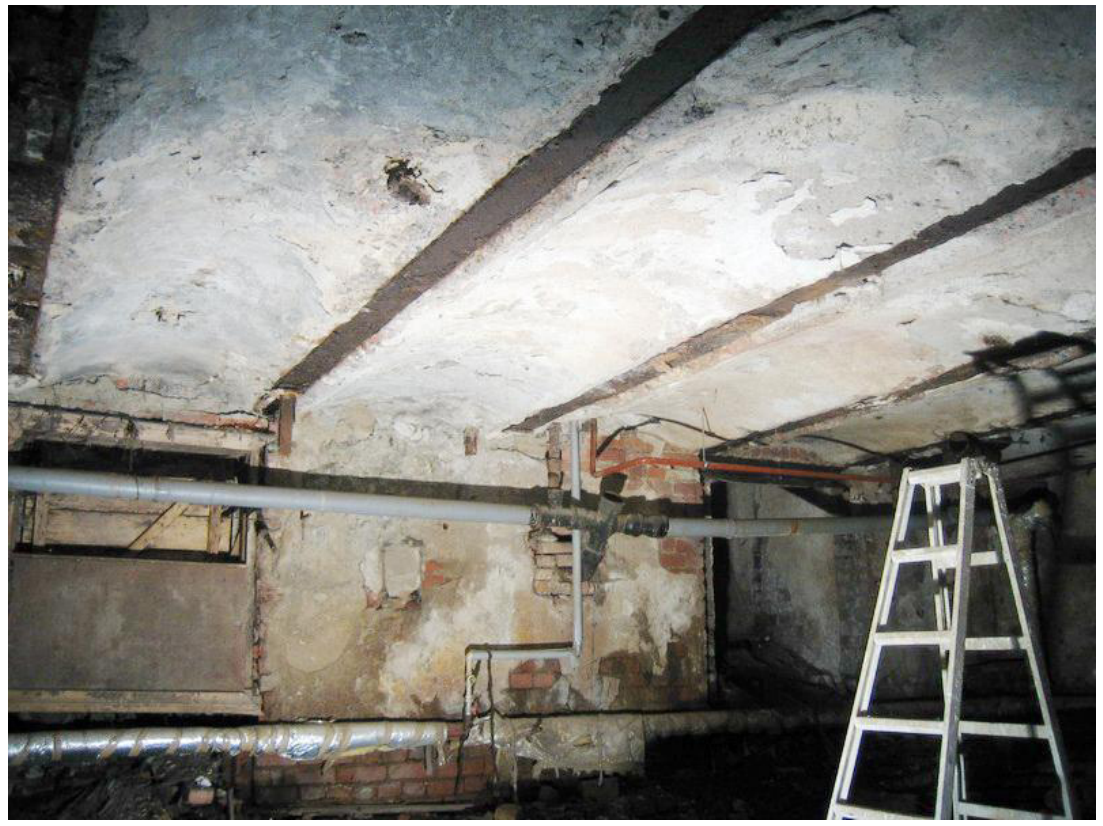

b)

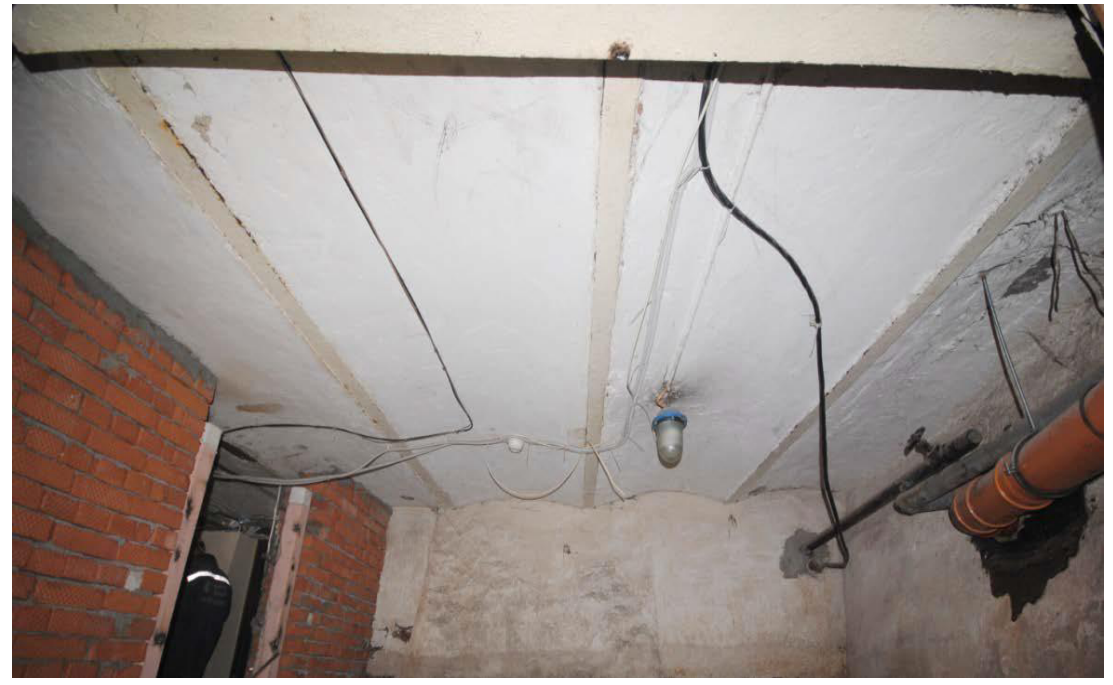

Fig. 1. a), b) Floor slab in the form of vaults over the steel beams [5]. [5].

The first of the abovementioned types of floor structures is one of a frequent occurrence

In order to analyze the temperature field, the floor structure described in [7] (Figure 3). Spacing between the beams is assumed as $1.2 \mathrm{~m}$. 
a)

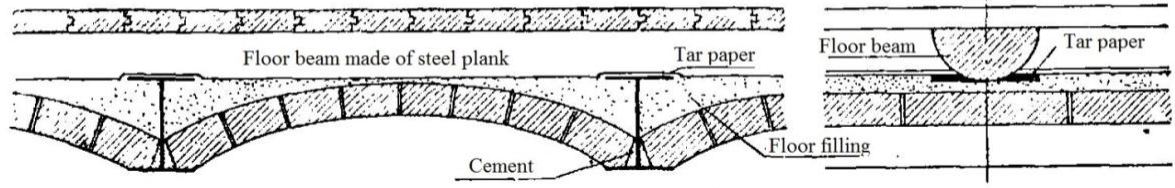

b)

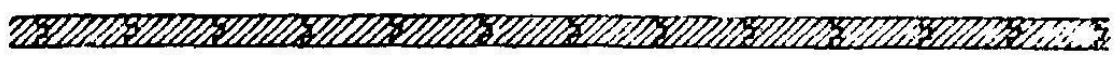

Floor beam made of steel plank

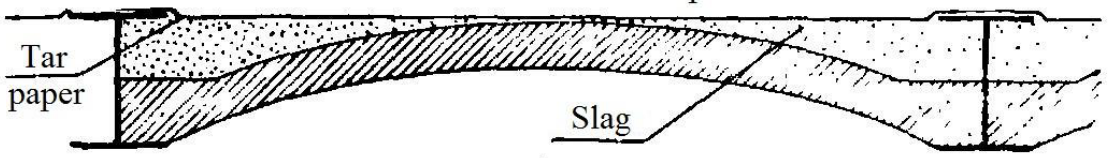

c)

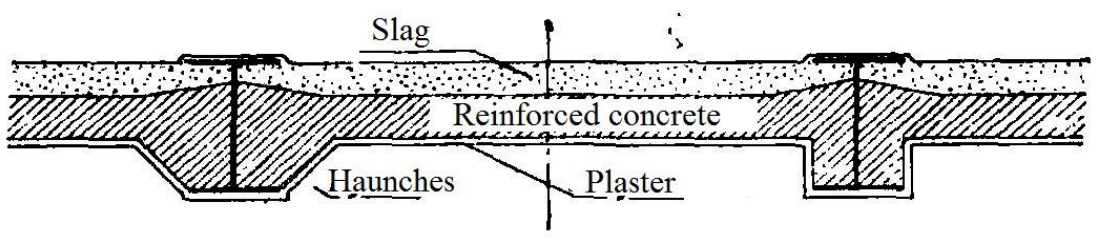

d)

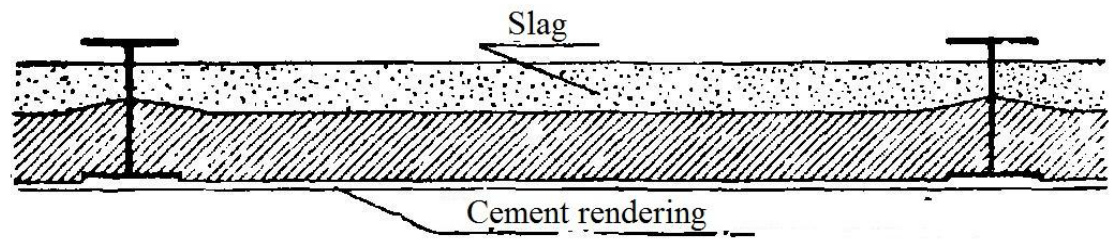

Fig. 2. Basement floor structures [6]

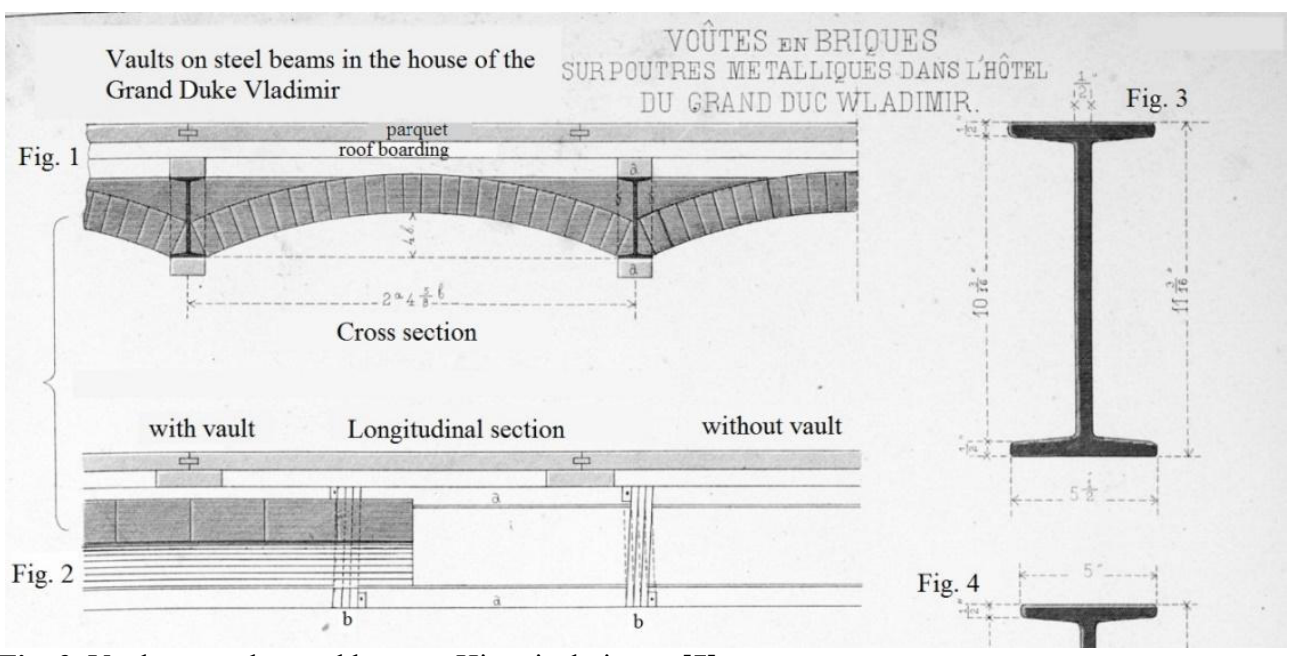

Fig. 3. Vaults over the steel beams. Historical picture [7]. 


\section{Results}

Determine the heat transfer performance uniformity factor for the basement floor. In order to determine the heat transfer performance uniformity factor temperature field calculation was performed as well as the calculation of heat flows in floor structure according to the «ELCUT» program for the reference temperature of the internal air of $20^{\circ} \mathrm{C}$ and the air temperature in the cellar $2^{\circ} \mathrm{C}$ (Figure 4).

Heat transfer performance uniformity factor $r$ is a dimensionless index, numerically equal to the ratio of heat flow through a fragment of inhomogeneous building envelope structure to the heat flow through the conventional homogeneous envelope structure designs with the same surface area as that of the fragment.

As a result of the calculation the value of the heat transfer performance uniformity factor the building envelope was determined, taking into account the impact of beams, $r=1$. As a conventional homogeneous building envelope structure the thinnest floor structure between the beams is considered.

The specific thermal resistance of the basement floor:

$$
R_{o}^{s p}=R_{o} \cdot r=R_{o}, \mathrm{~m}^{2} \cdot{ }^{\circ} \mathrm{C} / \mathrm{W}
$$

Where $R_{o}$ is the thermal resistance of homogeneous building envelope structure which was determined for the thinnest floor structure, $\mathrm{m}^{2} \cdot{ }^{\circ} \mathrm{C} / \mathrm{W}$.

It should also be noted that the considered basement floor structure above provides uniform temperature field on the floor surface in the room (Figure 4, a).

a)

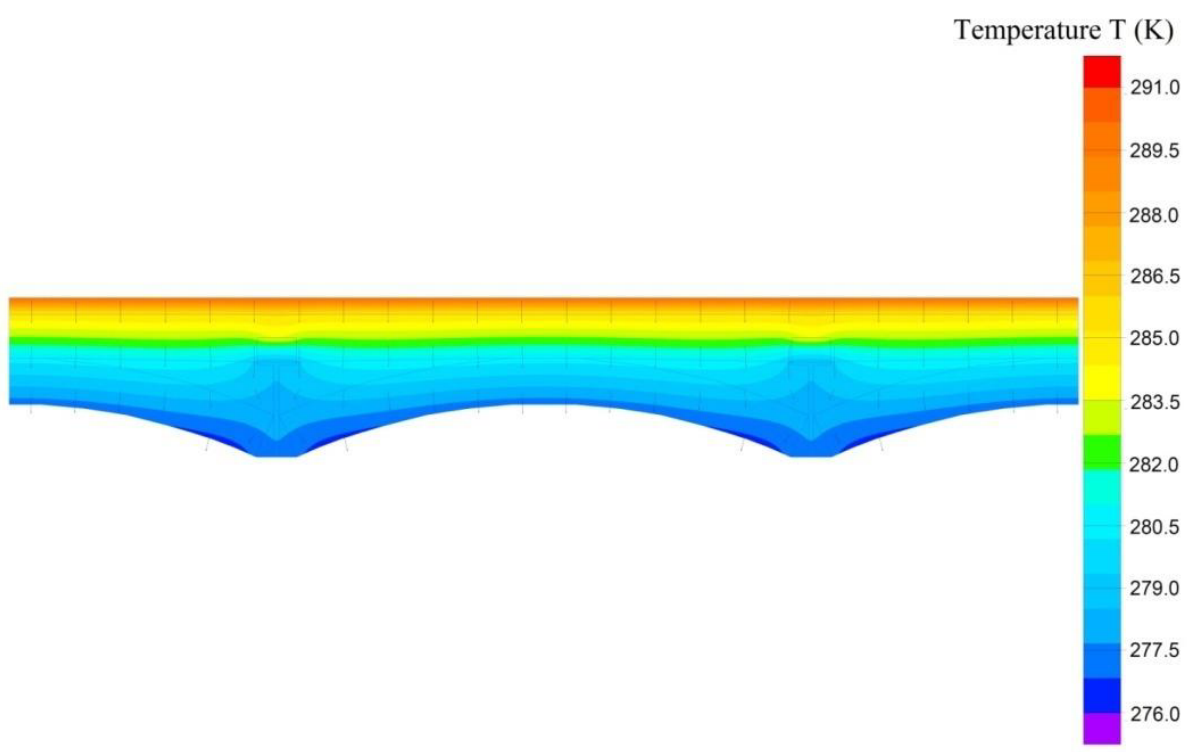


b)

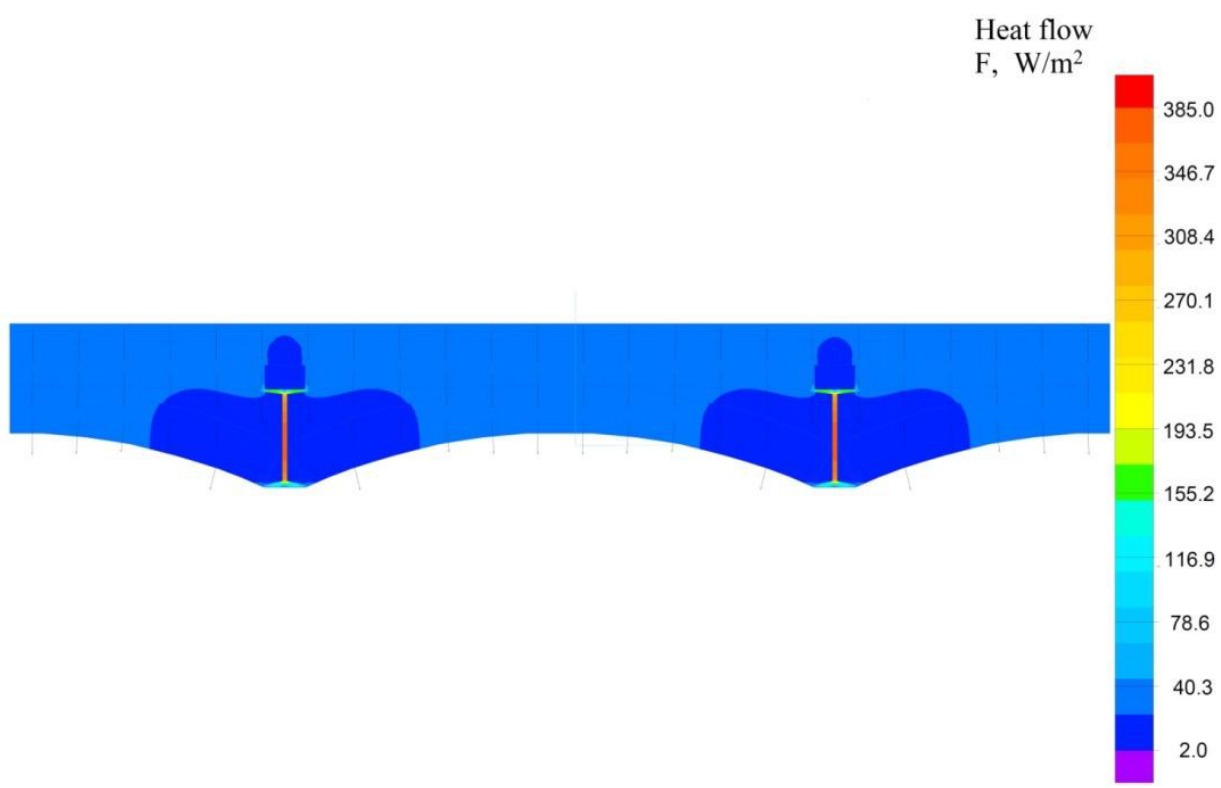

Fig. 4. Temperature field (a) and distribution of heat flows (b) in the structure of the attic floor.

\section{Conclusion}

1. The heat transfer performance uniformity factorfor the basement floor made of brick vaults in residential historic buildings was determined.The heat transfer performance uniformity factor for the considered basement floor structureis assumed as 1 for the thermal calculation. Calculation of floor thermal resistance is performedfor the structure type with the smallest thickness.

2. It wasdetermined that the temperature field on the floor surface in the premises is homogeneous.

\section{References}

1. A. Martínez-Molina, I. Tort-Ausina, S. Cho, J.L.Vivancos, Renewable and Sustainable Energy Reviews 61, 70-85(2016)

2. C. Cornaro, V. A.Puggioni, R. M.Strollo, Journal of Building Engineering 6, 1728(2016)

3. J. Berger, H. R.B. Orlande, N. Mendes, S.Guernouti, Building and Environment 106, 327-339(2016)

4. M. Harrestrup, S. Svendsen, Building and Environment 85, 123-133(2015)

5. E.A. Laptev, A.V. Ulybin, Osobennosti obsledovaniya perekrytiy po stal'nym balkam s nakatom $v$ vide svodikov. Obsledovanie zdaniy i sooruzheniy: problemy i puti ikh resheniya (SPbPU, S.Peterburg, 2015)

6. L.K.Martensa,Tekhnicheskaya entsiklopediya (OGIZ RSFSR, Moscow,1932)

7. Arkhitekturnyy i khudozhestvenno-tekhnicheskiy zhurnal, izdavaemyy S.-Peterburgskim obshchestvom arkhitektorov (Zodchiy,S.Peterburg, 1872) 